\title{
Chlorpromazine-methamphetamine antagonism in a non-discriminated avoidance schedule ${ }^{1,2}$
}

HUGH BROWN

DEPARTMENT OF PHARMACOLOGY, ABBOTT LABORATORIES, NORTH CHICAGO, ILLINOIS

Rats responding under a non-discriminated avoidance schedule having a 20 sec. shock-shock and shock-response interval were dosed with $3.0 \mathrm{mg} / \mathrm{kg}$ chlorpromazine. The resultant depression of response rate was antagonized with various doses of methamphetamine thus developing a doseeffect antagonistic relationship. These data did not reflect any marked increase in drug action sensitivity over that obtained from discriminated avoidance or food reinforced techniques.

When comparing drug effects on behavior maintained by non-discriminated (no pre-shock warning stimulus) and discriminated (pre-shock warning stimulus) avoidance schedules, the former has appeared to be quantitatively more sensitive (Heise \& Boff, 1962). It has also been shown that non-discriminated (also called continuous or "Sidman") avoidance schedules can reflect both antagonistic (Heise \& Boff, 1962) and synergistic (Carlton \& Didamo, 1961) drug interactions; however, superior sensitivity in this regard has not been demonstrated.

The most universally established drug interaction, in regard to behavioral effects, is the antagonistic relationship between chlorpromazine and the amphetamines. It has been reported that both food reinforced fixed ratio schedules (Brown, 1963; Davis, 1965) and discriminated electroshock avoidance (Jenney \& Healy, 1959; Teitelbaum \& Derks, 1959) reflect the antagonistic interaction between these two drugs.

The present report utilized this established relationship in a non-discriminated avoidance paradigm to determine if improved sensitivity over either discriminated avoidance or a food reinforced operant would be indicated in terms of a drug interaction.

\section{Method}

Six male Sprague-Dawley rats, weighing 200-250 gm at the beginning of the experiment, served as Ss. They were subjected to daily $4 \mathrm{hr}$. sessions in a conventional electro-mechanically automated small animal experimental chamber containing only a single response lever. Brief non-escapable footshocks (0.3 sec., 1000 V, $3.0 \mathrm{ma})$ were delivered through a scrambler to the stainless steel grid floor. The interval between shocks was 20 sec. A lever response delayed the shock for $20 \mathrm{sec}$. (Sidman, 1953).

After behavior stabilized (consistent daily $90 \%$ avoidance), dose-effect curves were established for chlorpromazine hydrochloride and methamphetamine hydrochloride randomly administered immediately prior to a $4 \mathrm{hr}$. session. Doses of methamphetamine were then used to antagonize the effects of chlorpromazine. Each animal was given an initial $1.5 \mathrm{hr}$. session. This was repeated immediately following administration of a markedly depressing dose of $(3.0 \mathrm{mg} / \mathrm{kg})$ chlorpromazine. Finally, a $1 \mathrm{hr}$. session was instituted following methamphetamine injection $(0.25-1.0 \mathrm{mg} / \mathrm{kg})$. The procedure thus established a continual sequence of control $\rightarrow$ agonist $\rightarrow$ antagonist.

All injections were intraperitoneal in a volume of $0.1 \mathrm{mg} / 100 \mathrm{gm}$ body weight from $0.9 \% \mathrm{NaCl}$ solutions. Drug sessions were spaced at least $96 \mathrm{hr}$. with saline injections being maintained in the interval. Each dose of every drug and drug combination was tested at least three times.

\section{Results and Discussion}

As the dose-effect curves in terms of responses per minute (Fig. 1) show, the efficacy of both drugs is compatible with their usual effects in operant avoidance situations (Dews \& Morse, 1961), i.e., chlorpromazine depresses response rates, amphetamine increases responding. The potency values are similarly characteristic for other non-discriminated avoidance studies involving these drugs (Heise \& Boff, 1962).

The antagonism data are also clearly dose dependent
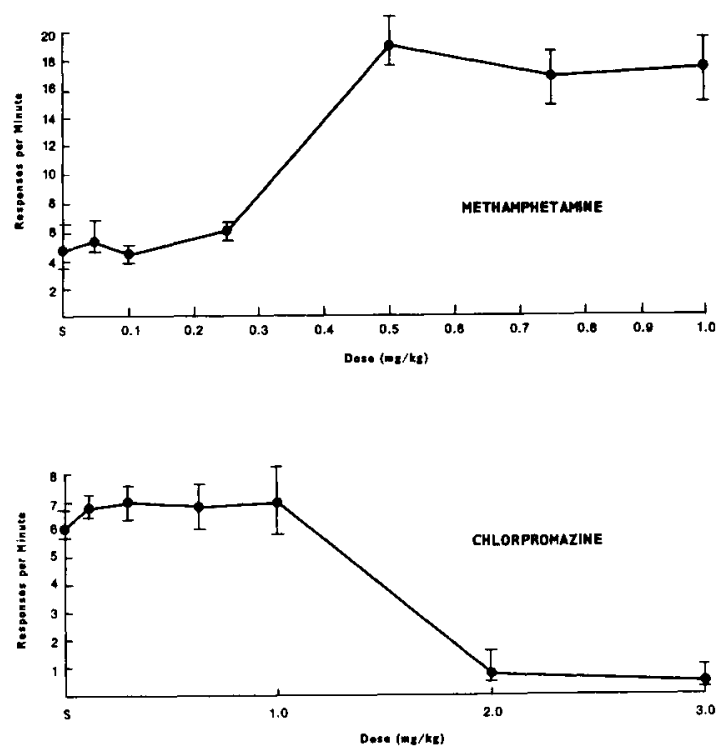

Fig. 1. Dose effect curves of methamphetamine (above) and chlopromazine (below) in terms of response rate. $S$ is the saline control value. Each point represents the mean of three session for each of six rats. Vertical ordinates represent range of values for each point. 


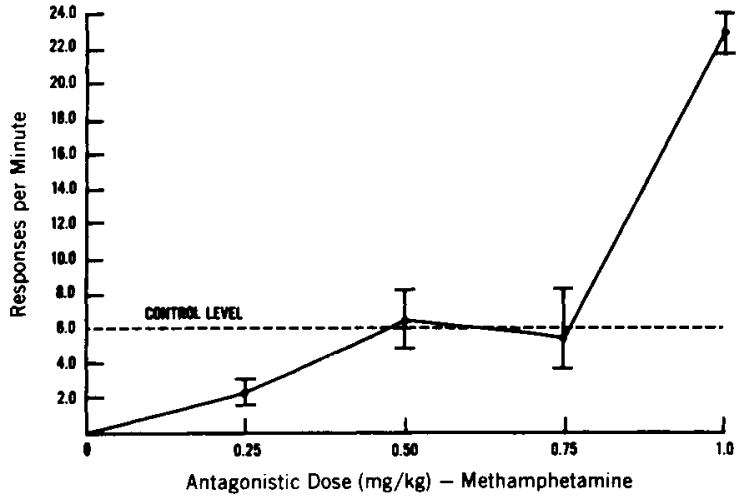

Fig. 2. Dose effect curve for the chlorpromazine-methamphetamine antagonism sessi us. The abscissa represents the doses of methamphetamine used to antagonize $3.0 \mathrm{mg} / \mathrm{kg}$ chlorpromazine. Each point represents the mean of at least three sessions for each of six rats. The control level is the overall mean control value. Vertical ordinates represent range of values for each point.

(Fig. 2). Maximal antagonism of the $3.0 \mathrm{mg} / \mathrm{kg}$ dose of chlorpromazine, in terms of re-establishing pre-drug response levels, occurred with 0.5 and $0.75 \mathrm{mg} / \mathrm{kg}$ methamphetamine.

Compared with the amphetamine doses employed in the discriminated avoidance studies of Jenney \& Healy (1959) and Teitelbaum \& Derks (1959), and discounting any slight potency differences among the isomers and analogs involved, the values of the present study are approximately five times lower. The clorpromazine doses are similar except for Jenney \& Healy (1959); their chlorpromazine dose was twice that of the other studies. Thus, it would appear that non-discriminated avoidance is not universally more sensitive to drug interaction than discriminated avoidance.

When comparing the results of the present study to Brown's (1963) data for FR 10 food reinforced lever pressing, profound sensitivity differences are also not apparent. The dose of chlorpromazine is again similar, and the amphetamine dose is, again, approximately five times greater. However, in that study, a depressing, hence high, dose of amphetamine was employed as the agonist while the present study utilized low stimulatory doses as the antagonist. Also, it should be remembered that even though the pharmacologic action of these drugs and behavioral data (Davis, 1965) suggest they are mutually antagonistic, such an assumption cannotbe made a priori. Therefore, since a depressant dose of amphetamine and the opposite agonist-antagonist relationship were employed, direct comparison cannot be made with either the amphetamine effect or the antagonistic relationships described in this report. An analogous relationship could not be cuplicated in the present study because comparable depressant dose levels of amphetamine are lethal in electro-shock conditions (Weiss \& Laties, 1959).

\section{References}

Brown, H. d-Amphetamine-chlorpromazine antagonism in a food reinforced operant. J. exp. Anal. Behav., 1963, 6, 395-398.

Carlton, P. L., \& Didamo, P. Augmentation of the behavioral effects of amphetamine by atropine. J. pharmacol. exp. Therap., 1961, 134, 91-96.

Davis, J. L. Antagonism of a behavioral effect of d-amphetamine by chlorpromazine in the pigeon. J. exp. Anal. Behav., 1965, $8,325-327$.

Dews, P. B., \& Morse, W. H. Behavioral pharmacology. Ann. Rev. Pharmacol., 1961, 1, 145-174.

Heise, G. A., \& Boff, E. Continuous avoidance as a baseline for measuring behavioral effects of drugs. Psychopharmacologia, $1962,3,264-282$.

Jenny, E. H., \& Healy, S. T. Drug antagonists to chlorpromazine inhibition of the conditioned response. Fed. Proc., 1959, 18, 407.

Sidman, M. Avoidance conditioning with brief shock and no exteroceptive warning signal. Science, 1953, 118, 157-158.

Teitelbaum, P., \& Derks, P. The effect of amphetamine on forced drinking in rats. J. comp. physiol. Psychol., 1958, 51, 801-810.

Weiss, B., \& Laties, V. G. Amphetamine toxicity in rats subjected to aversive stimulation. Fed. Proc., 1959, 18, 457.

\section{Notes}

1. This work was done under Contract No. DA18-108-MMC-108(A) from U. S. Army Research Laboratories, Edgewood Arsenal, Edgewood, Maryland to FMC Corporation. Princeton, New Jersey with Abbott Laboratories as subcontractor.

2. In conducting the research reported herein, the investigators adhered to "Principles of Laboratory Animal Care" as established by the National Society for Medical Research.

3. The technical assistance of F. W. Remfry is gratefully acknowledged. 